\title{
Prevalence of iodine deficiency and goitre during pregnancy in east Hungary
}

\author{
E Mezosi, I Molnar ${ }^{3}$, A Jakab ${ }^{4}$, E Balogh ${ }^{1}$, Z Karanyi, Z Pakozdy ${ }^{1}$, P Nagy ${ }^{1}$, F Gyory $^{2}$, J Szabo, L Bajnok, \\ A Leovey, G Kakuk and E V Nagy
}

1st Department of Medicine, ${ }^{1}$ Department of Radiology and ${ }^{2} 1$ st Department of Surgery, Medical and Health Science Centre, University of Debrecen, Debrecen, Hungary, ${ }^{3} 3 r d$ Department of Medicine, Kenezy County Hospital, Debrecen, Hungary and ${ }^{4}$ Health Care System, Debrecen, Hungary

(Correspondence should be addressed to E V Nagy, 1st Department of Medicine, Medical and Health Science Centre, University of Debrecen, Debrecen, PO Box 19, H-4012, Hungary)

\begin{abstract}
Objective: To assess the iodine nutritional status and the prevalence of goitre during pregnancy in a region of Hungary that appeared to be iodine sufficient in previous studies.

Design: A cross-sectional voluntary screening study was organized in which 313 pregnant women participated.

Methods: Urine iodine concentration and the volume of the thyroid gland were measured in every woman. In the presence of low urinary iodine concentrations, goitre, or both, thyroid function tests were performed.

Results: Iodine deficiency was found in $57.1 \%$ of the pregnant women, and was severe in $15.6 \%$. The volume of the thyroid gland was enlarged in $19.2 \%$ of individuals. Nodular goitre was found in 17 women $(5.4 \%)$. The frequency of goitre and the mean thyroid volume were increased in the group of iodine-deficient women. In the 89 cases of iodine deficiency or goitre, thyrotrophin concentrations were in the normal range; however, the free triiodothyronine:free throxine ratio was increased in $97 \%$ of them, indicating that the thyroid gland was in a stimulated state in these individuals. Conclusions: Iodine deficiency with high prevalence of goitre was recognized among pregnant women in an area that previously appeared to be iodine sufficient. An unexpected mild iodine deficiency was also noted in the non-pregnant control group. Reassessment and continuous monitoring of iodine nutritional status is warranted even in populations that are apparently considered to be 'at no risk' of iodine deficiency, especially in pregnant women. Regular administration of iodine, starting at preconception or in early pregnancy and continuing during the period of nursing, is recommended in these regions.
\end{abstract}

European Journal of Endocrinology 143 479-483

\section{Introduction}

Iodine supply is inadequate in most parts of Hungary, except in small areas of the Great Plains (1-4). Several attempts have been made to eliminate this iodine deficiency (5). Since the 1970s, the issue of inadequate iodine intake has been publicized by several authors as a problem requiring immediate attention $(1-3)$. Iodized salt and iodine-containing tablets can be purchased on a voluntary basis; however, as no state-organized program has been developed, inadequate iodine intake has remained a nation-wide health problem. Previous studies found the region of Debrecen (which is situated on the Great Plains) to be an area of adequate iodine intake as judged by the low frequency of goitre in the population, except for a few clusters of small villages $(4-6)$
Previous investigations confirmed that the most detrimental effects of inadequate nutritional iodine intake appear in pregnant women and in children (7-9). Hormonal changes and metabolic demands during pregnancy result in alterations in the biochemical parameters of thyroid function (10). The effects of iodine deficiency become manifest even in geographical areas of borderline iodine supply, because the thyroid gland cannot meet the demand for increased production of thyroid hormone (10-13). The main changes in thyroid metabolism in pregnancy are well characterized (10-15). Iodine deficiency triggers compensatory stimulating events affecting the thyroid gland of both the mother and the fetus. With respect to long-term effects, the development of goitre is only of secondary importance; the detrimental effect of mild thyroid insufficiency (defined by a moderate decrease in 
maternal free thyroxine $\left(\mathrm{FT}_{4}\right)$ concentration) on the neuropsychological development of the child has been repeatedly emphasized $(9,16-22)$.

We assumed that, in a community with apparently sufficient iodine intake, the increased iodine demand during pregnancy might lead to manifest iodine deficiency in pregnant women. In the present study we show that the iodine nutritional status found in the general population may not reliably reflect the iodine supply of pregnant women living in the same region.

\section{Participants and methods}

\section{Participants}

We enrolled 313 pregnant women into a cross-sectional voluntary screening study, which was coordinated by the physicians and nurses of the Health Care System in Debrecen. The ages of the women were $26.8 \pm 5.2$ (range 17-47) years and the gestational ages were $23.6 \pm 7.9$ (6-39) weeks. Multivitamin products, which may contain iodine, are routinely offered to pregnant women by gynaecologists. The consumption of these drugs and the use of iodized salt were elicited by detailed history and four groups were established according to the form of iodine supplementation: group A, no iodine supplementation $(n=119)$; group $\mathrm{B}$, regular use of iodized salt, no consumption of iodinecontaining multivitamins $(n=50)$; group C, taking iodine-containing multivitamins, no use of iodized salt $(n=91)$; group $\mathrm{D}$, regular use of iodized salt and iodine-containing multivitamin tablets $(n=53)$. Overall, $46 \%$ of women consumed iodine-containing multivitamin products. The gestation times of those in the nonmultivitamin consuming groups (A and B: $24.6 \pm 8.1$ weeks) and the multivitamin consuming groups ( $\mathrm{C}$ and $\mathrm{D}$ : $23.9 \pm 7.4$ weeks) did not differ significantly.

To assess the iodine supply in the general population, samples from 220 non-pregnant women were also analysed.

\section{Methods}

Urine iodine concentration was determined from the first morning urine void, by the Sandell-Kolthoff colourimetric method (23). The iodine concentration of the urine was standardized against that of creatinine, urine creatinine concentrations being measured on the days of sampling. Urine specimens were stored at $-20^{\circ} \mathrm{C}$ until required for analysis. The iodine deficiency was regarded to be mild with urinary iodine concentration between 50 and $100 \mu \mathrm{g}$ iodine/g creatinine, moderate in the range $25-50 \mu \mathrm{g}$ iodine/g creatinine and severe when values were less than $25 \mu \mathrm{g}$ iodine/g creatinine.

Thyroid volume measurements were performed by ultrasound (Siemens Sonoline SL-1, 7.5 MHz linear transducer). Each lobe of the thyroid gland was assessed separately by measuring the three main diameters, and the total volume of the thyroid was calculated by the algorithm $\pi / 6 \times$ height $\times$ width $\times$ depth. The upper limit of normal thyroid volume was $18 \mathrm{ml}$.

In cases of urinary iodine less than $50 \mu \mathrm{g} / \mathrm{g}$ creatinine or diffuse or nodular goitre, further tests were offered to the expectant mothers; 89 of them were willing to continue the investigations. Thyroid-stimulating hormone (TSH) was assayed by a third-generation immunochemiluminometric assay and $\mathrm{FT}_{4}$ by a competitive-binding, one-step chemiluminescent immunoassay (both from Byk-Sangtec Diagnostica Gmbh \& Co., Dietzenbach, Germany). Free tri-iodothyronine $\left(\mathrm{FT}_{3}\right)$ was assayed by a two-step saturationcompetitive binding microparticulate enzyme immunoassay (Abbott Laboratories, Abbott Park, IL, USA).

\section{Data analysis}

The relationship between thyroid volume and iodine excretion was analysed statistically using ANOVA, and groups were compared using the Newman-Keuls test. The median test and the Pearson $\chi^{2}$ - test were applied to analyse the effect of iodine supplementation on urinary iodine excretion. The level of significance in all statistical tests was set at $P \leq 0.05$.

\section{Results}

\section{Urinary iodine excretion}

Iodine deficiency among pregnant women in the city of Debrecen was much more frequent than we had

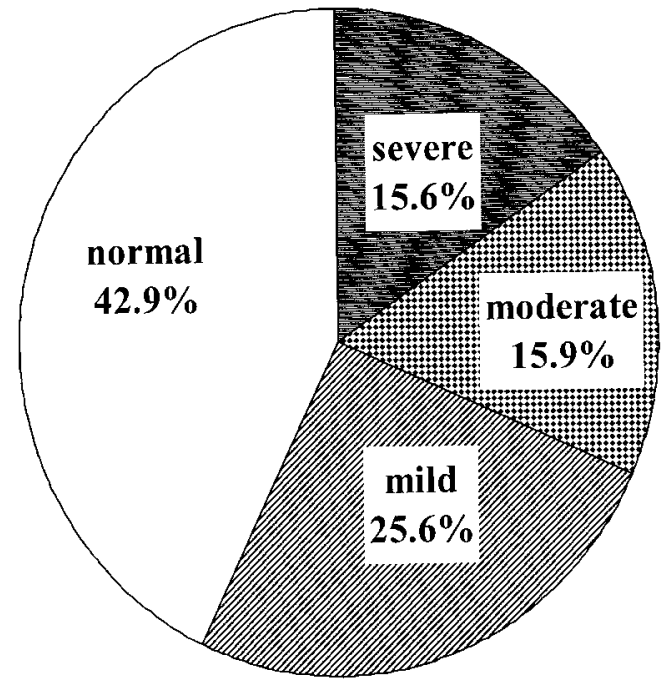

Figure 1 Urinary iodine concentrations in 313 pregnant women living in Debrecen. Severe iodine deficiency (urinary iodine $0-25 \mu \mathrm{g} / \mathrm{g}$ creatinine) was detected in $15.6 \%$ of the women, moderate deficiency $(25-50 \mu \mathrm{g}$ iodine/g creatinine) in $15.9 \%$ and mild deficiency (50-100 $\mu \mathrm{g}$ iodine/g creatinine) in $25.6 \%$. The urinary iodine excretion was normal (>100 $\mu \mathrm{g}$ iodine/g creatinine) in $42.9 \%$ of these pregnant women. 


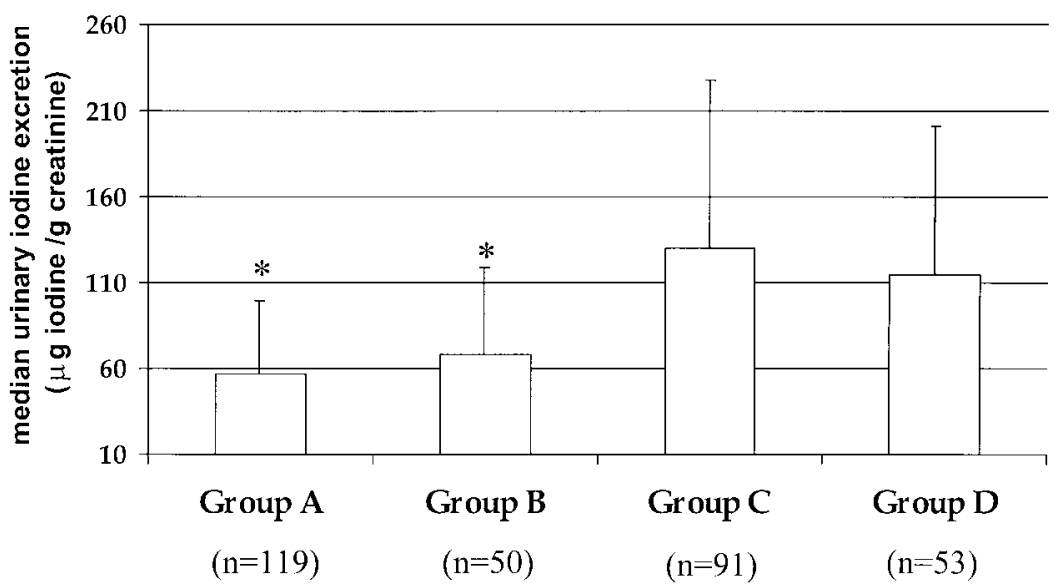

Figure 2 Urinary iodine excretion in women grouped according to their iodine supplementation. Group A: no iodine supplementation; group B: regular use of iodized salt; group C: consumption of iodinecontaining multivitamins, no use of iodized salt; group D: regular use of iodine-containing multivitamins and iodized salt. Data are presented as median+upper quartile. The median urinary iodine excretion was significantly lower in groups $A$ and $B$ than in groups $C$ and $D\left({ }^{*} P<0.01\right)$. The use of iodized salt did not influence the urinary iodine concentrations. No significant difference was found between groups $C$ and $D$. expected before the study (Fig. 1): normal urine iodine concentration was measured only in $42.9 \%$ of the women. The level of iodine deficiency was mild in $25.6 \%$, moderate in $15.9 \%$ and severe in $15.6 \%$ of pregnant women. The median urinary iodine excretion was $57,68,130$ and $115 \mu \mathrm{g} / \mathrm{g}$ creatinine in groups $\mathrm{A}, \mathrm{B}, \mathrm{C}$ and $\mathrm{D}$ respectively (Fig. 2); that in the control group of 220 non-pregnant woman was $82 \mu \mathrm{g}$ iodine/g creatinine. The regular use of iodized salt did not influence the median urinary iodine excretion, but the consumption of multivitamin drug products increased the urinary iodine concentrations significantly. No significant difference in the median urinary iodine excretion was found between groups $\mathrm{C}$ and $\mathrm{D}$ (consumption of iodine-containing multivitamins respectively without and with iodized salt), therefore we combined the results of groups $\mathrm{A}$ and $\mathrm{B}$, and those of groups $\mathrm{C}$ and $\mathrm{D}$ in further analyses. Although the frequency of iodine deficiency was lower in women

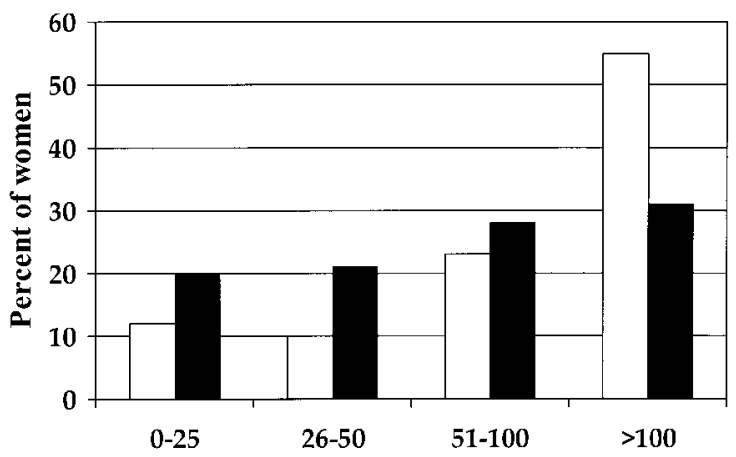

Urinary iodine concentration ( $\mu \mathrm{g}$ iodine/g creatinine)

Figure 3 The distribution of urinary iodine concentrations separately among pregnant women who were (open bars, $n=144$ ) or were not (solid bars, $n=169$ ) consuming iodine-containing multivitamins (150 $\mu \mathrm{g} /$ day). The prevalence of low urinary iodine excretion was significantly greater in the latter group $(P<0.01)$. Even with iodine replacement, only $55 \%$ of the women were iodine sufficient. taking iodine-containing multivitamins than in those without iodine supplementation, adequate iodine intake was measured only in 55\% of women who were taking regular multivitamin iodine supplementation (Fig. 3). Iodine deficiency was diagnosed in 69\% of expectant mothers without iodine-containing multivitamin consumption, and in $45 \%$ taking iodinecontaining multivitamins.

\section{Maternal thyroid ultrasound}

The volume of the thyroid gland was in excess of the normal value of $18 \mathrm{ml}$ in $19.2 \%$ of the women. Nodular goitre was diagnosed in 17 (5.4\%). The mean thyroid volume of women with severe iodine deficiency was significantly larger than that in the group with adequate iodine intake, and the frequency of goitre was increased in all groups with iodine deficiency (Fig. 4).

\section{Maternal thyroid parameters}

In 89 women with low urine iodine excretion or goitre, further thyroid tests were performed. The mean TSH was $1.11 \pm 0.54 \mathrm{mIU} / \mathrm{l}$, which is within the normal range of $0.3-3.0 \mathrm{mIU} / \mathrm{l}$. However, the $\mathrm{FT}_{3}: \mathrm{FT}_{4}$ ratio was remarkably increased at $0.45 \pm 0.13$, and was above the upper limit of normal (0.25) in 97\% of the women.

\section{Discussion}

Considering that previous studies have concluded that the region of Debrecen was an area of sufficient iodine supply $(1,2,4,5)$, it is striking that, on the basis of urinary iodine excretion, we found mild iodine deficiency in the non-pregnant female population. More importantly, $57.1 \%$ of pregnant women in Debrecen were found to be iodine deficient and $19.2 \%$ had goitre. One possible explanation is a change in available iodine 


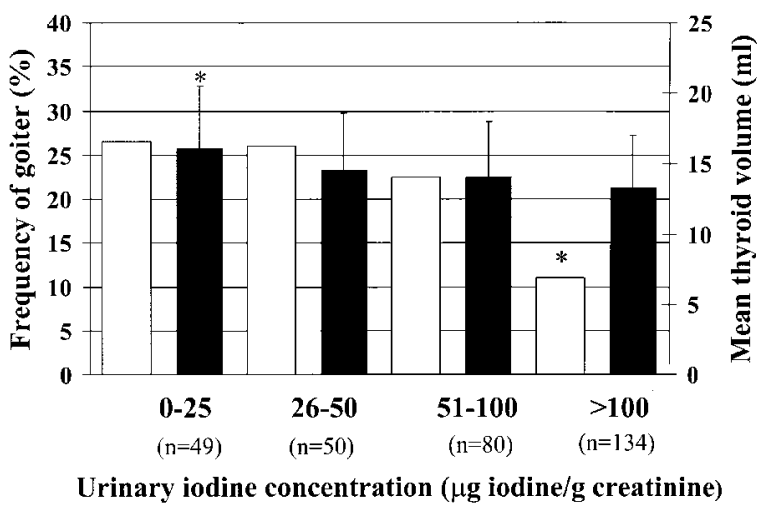

Figure 4 Frequency of goitre (open bars) and mean thyroid volume (solid bars) in relation to the urinary iodine concentration in pregnant women. Significant thyroid enlargement was found in those with severe iodine deficiency $\left({ }^{*} P=0.01\right)$. The frequency of goitre was increased in all groups with iodine deficiency $(P<0.01)$.

in this area. A decrease in iodine intake in the past 15 years has also been observed in the USA, resulting in low urinary iodine concentrations in $15 \%$ of women of childbearing age (24). In Hungary, where both iodized and non-iodized salts are available, iodized salt is not used during the industrial production of foodstuffs, and usually only a small part of a meal is prepared at home. In our study, the regular use of iodized salt at home before and during pregnancy did not result in an improvement in iodine nutritional status, as urinary iodine excretion in women supplementing their iodine intake did not differ significantly from that in women not taking any form of iodine replacement. Among pregnant women receiving no iodine supplementation or using only iodized salt at home, the prevalence of iodine deficiency was $69 \%$.

Nearly $50 \%$ of pregnant women involved in this study received iodine supplementation in the form of multivitamin tablets containing $150 \mu \mathrm{g}$ iodine, taken once a day. These products were offered as part of the routine obstetric regimen, and not with the specific purpose of counteracting iodine deficiency (as iodine deficiency had not been suspected). Even in pregnant women receiving this form of iodine supplementation, urinary iodine excretion was sufficient in only $55 \%$. The reason for this may be multifold. The recent WHO recommendation is for the daily nutritional intake of $200 \mu \mathrm{g}$ iodine during pregnancy and lactation (13). However, in goitre-endemic regions we would expect to encounter decreased iodine concentrations in the thyroid at the beginning of pregnancy (11). In such cases, favourable results are more likely to be achieved with 300-400 $\mu \mathrm{g}$ daily iodine. Compliance with the drug therapy is also an important factor. Finally, exact data are not available concerning the pharmacokinetic properties of the iodine-containing drug products. Our results demonstrated that occasional iodine supplementation in the form of multivitamins prescribed by gynaecologists was not adequate across the pregnant population as a whole. Conscious iodine supplementation therapy is necessary, with regular control of the compliance of women.

The urinary iodine excretion and the frequency of goitre in pregnant women in Debrecen were similar to those found by studies examining large populations around Brussels and in the southwest of France, which are marginally iodine-deficient regions (11, $25)$. These results indicate that a general survey of iodine nutritional status in pregnancy is recommended even in regions that are presumed to be iodine sufficient.

The causative role of iodine deficiency underlying the high frequency of goitre was strongly supported by the facts that the thyroid volume and the frequency of goitre were significantly larger in women with iodine deficiency than in the group with adequate iodine intake. As there are no methods available to estimate intrathyroid iodine pools on an individual basis, biochemical markers such as increased $\mathrm{FT}_{3}: \mathrm{FT}_{4}$ ratio, decreased $\mathrm{FT}_{4}$, increased thyroglobulin concentration and increased thyroid gland volume are useful surrogate tools (10-13). The $\mathrm{FT}_{3}: \mathrm{FT}_{4}$ ratio was increased in $97 \%$ of iodine-deficient women. This can be interpreted as the result of the pathological stimulation of the thyroid gland by iodine deficiency.

The association of low $\mathrm{FT}_{4}$ with a normal TSH value seems to be typical for iodine-deficient pregnancies. In late pregnancies, decreased $\mathrm{FT}_{4}$ concentrations with normal TSH were found in $17 \%$ and $33 \%$ of women in the southwest of France and in Belgium, respectively $(11,25)$. The exact cause of this phenomenon is not clearly understood. One explanation is that the determination of free hormones is influenced by the high serum concentration of thyroxin-binding globulin, resulting in false-positive low $\mathrm{FT}_{4}$ concentrations (26). Others concluded that iodine-deficient pregnant women suffered from true hypothyroxinaemia (14). The latter theory is supported by the fact that, in a region of adequate iodine intake, the prevalence of low $\mathrm{FT}_{4}$ concentration was only $0.3 \%(27)$.

In conclusion, in the area of Debrecen, which previously appeared to be iodine sufficient, $57.1 \%$ of the pregnant women suffered from iodine deficiency and 19.2\% had goitre. An unexpected mild iodine deficiency was also noted in the non-pregnant control group. The home usage of iodized salt does not seem to improve appropriately the iodine nutritional status in pregnancy, and occasional iodine supplementation in the form of multivitamin tablets resulted in partial success. Reassessment and continuous monitoring of iodine nutritional status in pregnancy is warranted even in populations that are apparently considered to be 'at no risk' of iodine deficiency. Regular administration of iodine, starting at preconception or in early pregnancy and continuing during the period of nursing, is recommended in these regions. 


\section{Acknowledgements}

The authors are grateful to Merck KG \& A for providing the mobile ultrasound unit, which was used throughout the study.

\section{References}

1 Péter F. Status of iodine nutrition of Hungary. In: Iodine Deficiency in Europe, pp 377-382. Eds F Delange, J-T Dunn \& D Glinoer. New York, London: Plenum Press, 1993.

2 Sajgo M \& Farkas I. Iodine content of drinking water and indicators of iodine supply of Hungarian population (in Hungarian). Egészségtudomány 199034 28-33.

3 Szechenyi-Nagy I \& Peter F. Ultrasonic study of thyroid volume in Budapest children (in Hungarian; abstract in English). Orvosi Hetilap 1993134 797-801.

4 Banfi J \& Balazs G. Data on the prevalence of endemic goitre in the eastern part of Hungary (in Hungarian). Népegészségügy 196546 196-201.

5 Remenárné Balogh I \& Kertai P. Fifteen years of the prophylaxis of goitre in Hungary (in Hungarian). Orvosi Hetilap 1968109 1597-1601.

6 Straub J. Biochemical investigation of endemic goitre in Bodahegy village (in Hungarian). Orvosi Hetilap 193074 480-483.

7 Delange F, Dunn JT \& Glinoer D. Iodine Deficiency in Europe. A Continuing Concern. New York, London: Plenum Press, 1993.

8 Delange F. The disorders induced by iodine deficiency. Thyroid 19944 107-128.

9 Fenzi GF, Giusti LF, Aghini-Lombardi F, Bartalena L, Marcocci C, Santini F et al. Neuropsychological assessment in schoolchildren from an area of moderate iodine deficiency. Journal of Endocrinological Investigation 199013 427-431.

10 Glinoer D, De Nayer P, Bourdoux P, Lemone M, Robyn C, Van Steirteghem A et al. Regulation of maternal thyroid during pregnancy. Journal of Clinical Endocrinology and Metabolism 1990 $71276-287$.

11 Glinoer D, Delange F, Laboureur I, De Nayer P, Lejeune B, Kinthaert J et al. Maternal and neonatal thyroid function at birth in an area of marginally low iodine intake. Journal of Clinical Endocrinology and Metabolism 199275 800-805.

12 Glinoer D \& Lemone M. Goitre and pregnancy: a new insight into an old problem. Thyroid 19922 65-70.

13 Glinoer D. The regulation of thyroid function in pregnancy: pathways of endocrine adaptation from physiology to pathology. Endocrine Reviews 199718 404-433.

14 Glinoer D. What happens to the normal thyroid during pregnancy? Thyroid $19999631-635$.
15 Smyth PPA. Variation in iodine handling during normal pregnancy. Thyroid $19999637-642$.

16 Cao XY, Jiang XM, Dou ZH, Rakeman MA, Zhang ML, O'Donnell K et al. Timing of vulnerability of brain to iodine deficiency in endemic cretinism. New England Journal of Medicine 1994331 1739-1744.

17 Pop VJ, Kuijpens JL, van Baar AL, Verkerk G, van Son MM, de Vijlder JJ et al. Low maternal free thyroxine concentrations during early pregnancy are associated with impaired psychomotor development in infancy. Clinical Endocrinology 199950149 155.

18 Haddow JE, Glenn MD, Palomaki E, Walter BS, Allan C, Josephine MD et al. Maternal thyroid deficiency during pregnancy and subsequent neuropsychological development of the child. New England Journal of Medicine 1999341 549-555.

19 Lazarus JH. Thyroid hormone and intellectual development: a clinician's view. Thyroid 1999 9 659-660.

20 Brenat GA. Maternal hypothyroidism: recognition and management. Thyroid $19999661-665$.

21 Vermiglio F, Lo Presti VP, Castagna MG, Violi MA, Moleti M, Finocchiaro MD et al. Increased risk of maternal thyroid failure with pregnancy progression in an iodine deficient area with major iodine deficiency disorders. Thyroid 19999 19-24.

22 Brent GA. Maternal hypothyroidism: recogniton and management. Thyroid $19999661-665$.

23 Sandell EB \& Kolthoff IM. Micro determination of iodine by a catalytic method. Mikrochemica Acta 1937 1 9-25.

24 Hollowell JG, Staehling NW, Hannon WH, Flanders DW, Gunter EW, Maberly GF et al. Iodine nutrition in the United States. Trends and public health implications: iodine excretion data from National Health and Nutrition Examination Surveys I and III (1971-1974 and 1988-1994). Journal of Clinical Endocrinology and Metabolism 199883 3401-3408.

25 Caron P, Hoff M, Bazzi S, Dufor A, Faure G, Ghandour I et al. Urinary iodine excretion during normal pregnancy in healthy women living in the southwest of France: correlation with maternal thyroid parameters. Thyroid 19977 749-754.

26 Nakagawa T, Matsumura K, Takeda K, Shinoda N, Matsuda A \& Matsushita T. Effect of stripping thyroxin from thyroxin-binding globulin on the measurement of free thyroxin in serum by equilibrium dialysis and by radioimmunoassay. Clinical Chemistry $199136313-318$.

27 Klein RZ, Haddow JE, Faix JD, Brown RS, Hermos RJ, Pulkkinen A et al. Prevalence of thyroid deficiency in pregnant women. Clinical Endocrinology $19913541-46$.

Received 21 February 2000

Accepted 29 June 2000 